This item was submitted to Loughborough's Research Repository by the author.

Items in Figshare are protected by copyright, with all rights reserved, unless otherwise indicated.

\title{
Current perspectives on profiling and enhancing wheelchair court-sport performance
}

\section{PLEASE CITE THE PUBLISHED VERSION}

http://dx.doi.org/10.1123/ijspp.2016-0231

\section{PUBLISHER}

(c) Human Kinetics Publishing as accepted for publication

\section{VERSION}

AM (Accepted Manuscript)

\section{PUBLISHER STATEMENT}

This work is made available according to the conditions of the Creative Commons Attribution-NonCommercialNoDerivatives 4.0 International (CC BY-NC-ND 4.0) licence. Full details of this licence are available at: https://creativecommons.org/licenses/by-nc-nd/4.0/

\section{LICENCE}

CC BY-NC-ND 4.0

\section{REPOSITORY RECORD}

Paulson, Thomas A.W., and Victoria L. Goosey-Tolfrey. 2019. "Current Perspectives on Profiling and Enhancing Wheelchair Court-sport Performance”. figshare. https://hdl.handle.net/2134/22116. 
Current perspectives on profiling and enhancing wheelchair court-sport performance

\begin{tabular}{|r|l|}
\hline Journal: & International Journal of Sports Physiology and Performance \\
\hline Manuscript ID & IJSPP.2016-0231.R1 \\
\hline Manuscript Type: & Invited Brief Review \\
\hline Keywords: & $\begin{array}{l}\text { Paralympic, wheelchair rugby, wheelchair basketball, wheelchair tennis, } \\
\text { physical capacity, training monitoring }\end{array}$ \\
\hline \multicolumn{2}{|l}{} \\
\hline
\end{tabular}


1 Current perspectives on profiling and enhancing wheelchair court-sport performance

2

3 Thomas Paulson \& Victoria Goosey-Tolfrey

4

5 The Peter Harrison Centre for Disability Sport, School of Sport, Exercise and Health

6 Sciences, Loughborough University, Loughborough, Leicestershire, LE11 3TU, England, 7 UK.

Text-only word count (max 4500): $4335 \underline{4576}$

14 Number of figures and tables: 2 Figures \& 2 Tables

\section{References: 6154}

Direct correspondence to: 


\section{Abstract}

33 Despite the growing interest in Paralympic sport, the evidence-base for supporting elite 34 wheelchair sport performance remains in its infancy when compared to able-bodied (AB) sport. Subsequently, current practice is often based on theory adapted from AB guidelines, with a heavy reliance on anecdotal evidence and practitioner experience. Many principles in training prescription and performance monitoring with wheelchair athletes are directly transferable from $\mathrm{AB}$ practice, including the periodisation and tapering of athlete loads around competition. Yet, a consideration for the physiological consequences of an athlete's impairment and the interface between athlete and their equipment are vital when targeting interventions to optimise in-competition performance. Researchers and practitioners are faced with the challenge of identifying and implementing reliable protocols that detect small but meaningful changes in impairment-specific physical capacities and on-court performance. Technologies to profile both linear and rotational on-court performance are an essential component of sports science support in order to understand sport-specific movement profiles and prescribe training intensities. In addition, an individualised approach to the prescription of athlete training and optimisation of the 'wheelchair/user interface' is required, accounting for an athlete's anthropometrics, sports classification and positional role on court. As well as enhancing physical capacities, interventions must also focus on the integration of the athlete and their equipment as well as techniques for limiting environmental influence on

51 performance. Taken together, the optimisation of wheelchair sport performance requires a multi-disciplinary approach based on the individual requirements of each athlete. 


\section{Introduction}

58 Since its inception at the Stoke Mandeville games in 1948, the Paralympic movement has 59 experienced a dramatic growth as a platform for sport in individuals with a physical 60 impairment. ${ }^{1}$ At the Rio 2016 Paralympic games, over around 4350000 athletes from 176

61 countries are expected to compete for 528 medals in one of the world's largest sporting 62 events. The rapid expansion in participation levels and public interest over recent decades has 63 been matched by a continued advancement in the standard of elite competition. The latter is 64 supported by the evolution of technical aids and equipment ${ }^{2}$ and an increasingly specialised 65 approach to sports science and sports medicine support. ${ }^{3,4}$

Despite the growing interest in Paralympic sport, the evidence-base for supporting wheelchair sport performance remains in its infancy when compared to able-bodied (AB) sport. A lack of resource as well as small, heterogeneous pools of elite athletes often inhibits the publication of scientific data collected in performance settings. Restrictions on data sharing within high performance systems also limit the availability of information detailing physiological capabilities and training practices of elite performers. Subsequently, current practice is often based on theory adapted from $\mathrm{AB}$ guidelines, with a heavy reliance on anecdotal evidence

73 and practitioner experience. ${ }^{5}$ Many principles in training prescription and performance monitoring are directly transferable between $\mathrm{AB}$ and wheelchair-based sport, including the periodisation and tapering of athlete training loads around competition. Yet, a consideration for the physiological consequences of an athlete's impairment and the interface between

77 athlete and their equipment are vital when targeting interventions to optimise in-competition 78 performance (see Figure 1 for overview).

79 The wheelchair sports currently receiving the most attention in the scientific literature are the

$80 \mid$ 'court sports' (i.e. basketball, rugby and tennis). Wheelchair basketball (WB) is a team sport 
81 designed for athletes who have a lower limb physical impairment that prevents running, jumping and pivoting, including paraplegia ${ }_{2}$ er -musculoskeletal conditions, spina bifida, amputation and poliomyelitis. ${ }^{6}$ Wheelchair rugby (WR) is a team sport played by individuals with an impairment that affects all four limbs, including cervical spinal cord injuries (tetraplegia), multiple amputations, polio, cerebral palsy and other neurological disorders. ${ }^{6}$ Wheelchair tennis (WT) is played in an open class (athletes with a range of impairments, such as amputations or thoracic/lumbar spinal cord injuries (paraplegia)) and the quad division (athletes with tetraplegia or upper extremity impairment) ${ }^{6}$. A wider discussion on the functional classifications systems within each sport is beyond the scope of this review and is provided elsewhere. ${ }^{6}$ Importantly the aforementioned sports present similarities in terms of the intermittent movement dynamics of on-court performance and the need to optimise the interface between an individual athlete and their equipment. sport specific movement dynamics. This review will outline scientific evidence and current perspectives on the profiling and enhancing physical performance in the court sports. Specifically, this review will focus on i) laboratory and field based assessments of physical capacity related to court-sport performance; ii) techniques and technologies available for profiling on-court physical performance and iii) the evidence base for targeted interventions aimed at enhancing physical performance, including training prescription, equipment innovations and thermoregulation.

\section{Profiling physical capacity and performance}

101 An athlete's impairment type and anthropometrics have a large influence on what physical attributes may be trainable in a sport-specific context (Figure 1). The functional classification systems within wheelchair sports are designed to minimise the impact of eligible impairment types on the outcome of competition and to promote equality in competition. ${ }^{1,6}$ However, the heterogeneity in impairment types competing within the same classification and/or sporting 
106 discipline presents a unique challenge for coaches and practitioners when considering 107 'benchmarks' of physical performance (e.g. tetraplegia vs. cerebral palsy). Furthermore, 108 wheeled sports performance requires the integration of both the athlete and their equipment 109 into one functioning unit, known as the 'wheelchair-user interface'. Researchers and 110 practitioners are faced with the challenge of identifying and implementing reliable protocols 111 that allow for differences in classification and detect small but meaningful changes in 112 impairment-specific physical capacities and on-court performance.

$\{[$ Insert Figure 1 here $]\}$

\section{Impairment-specific characteristics}

115 Physical capacity has previously been described as the ability of the musculoskeletal, 116 neurological/cerebral, cardiovascular and respiratory systems to perform a level of physical work. Spinal cord injury (SCI) is the most widely researched impairment, with physiological measures of aerobic capacity (peak oxygen uptake $\left(\dot{\mathrm{V}}_{2 \text { peak }}\right)$ and aerobic power), anaerobic capacity (peak power) and strength inversely related to lesion level and injury completeness. ${ }^{7}$

120 The lesion-level dependent loss of upper limb $(<\mathrm{C} 7-8)$, respiratory and trunk $(<\mathrm{T} 12)$ function

121 determines the ability of muscle groups to contribute to physical work output. In some cases asymmetry in remaining upper-limb or trunk function may reduce bilateral force production and should be assessed during initial functional movement screenings. The redistribution of blood during exercise in individuals with a SCI is impaired due to the lack of sympathetic vasoconstriction in inactive tissue below the lesion level. ${ }^{8}$ In athletes with paraplegia cardiac output $(\dot{\mathrm{Q}})$ is maintained by elevations in resting and submaximal $\mathrm{HR}^{8}{ }^{8}$ In athletes with 127 complete tetraplegia, the redistribution of blood and ability to elevate $\dot{\mathrm{Q}}$ is further limited due 128 to the loss of autonomic control of vessels in the abdominal bed and cardiac tissue. ${ }^{9}$ A SCI above T5 results in the loss of sympathetic outflow to the heart and maximal heart rates 
130 (HRpeak) of $100-140 \mathrm{~b} \cdot \mathrm{min}^{-1}$ are achieved primarily by the withdrawal of parasympathetic

131 tone. ${ }^{8,9}$ Recently, the partial preservation of descending sympathetic control was found to be 132 strongly correlated with indices of exercise performance, including 4-min push distance, 133 HRpeak, and $\dot{\mathrm{VO}}_{2 \text { peak. }}{ }^{9}$ These findings occurred in athletes neurologically motor and sensory complete spinal lesions, suggesting 'autonomic completeness' is an important factor in determining physical performance. ${ }^{9}$

From a medical perspective the loss of autonomic function following high thoracic and cervical level injury presents two distinct challenges to health and performance; namely autonomic dysreflexia and impaired thermoregulation. Autonomic dysreflexia is a potentially life-threatening bout of uncontrolled hypertension resulting from severe vasoconstriction and cardiac stimulation in response to a painful/noxious stimulus below the lesion level. ${ }^{4}$ The voluntary inducement of autonomic dysreflexia to enhance performance, known as 'boosting' is regarded as violation of anti-doping regulations. ${ }^{4}$ Reduced sympathetic input to the thermoregulatory centre also presents a loss of sweating capacity and loss of vasomotor control for redistribution of blood below the level of the spinal lesion. ${ }^{4,8}$ This compromised thermoregulatory response provides a greater risk of heat illness when compared with $\mathrm{AB}$ athletes and requires specific interventions to maintain health and performance (discussed further later). ${ }^{10,11}$

In contrast, those with lower and/or upper limb deficiency (e.g. amputee) may remain neurologically and physiologically intact, with cardiovascular responses similar to those observed in $\mathrm{AB}$ athletes. Importantly, the preservation of trunk function provides stability and contributes to the generation of momentum when performing high intensity activities, including accelerations or rotations. $\frac{12}{}$ Athletes with cerebral palsy $(\mathrm{CP})$ or central neurologic 153 injury, such as stroke, have a variety of impairment in sensation, motor control and 
154 communication ranging from mild to severe. ${ }^{4}$ From a motor control perspective, athletes

155 typically present an increased muscle tone or spasticity and impaired co-ordination leading to 156 muscle imbalance and reduced muscle power. ${ }^{4,13}$ The inhibited lactate release from spastic 157 muscle and aforementioned motor impairments may influence the reliability of protocols for 158 assessing aerobic and anaerobic capacity, yet wheelchair ergometry-specific evidence is 159 limited. ${ }^{13}$ Greater focus is required on the role of impaired motor-co-ordination on wheelchair 160 propulsion kinematics in athletes with CP.

Field vs. Laboratory assessments

In the assessment of an athlete's physical capacity there is a conflict between the higher reliability and lower ecological validity of laboratory compared to field-based protocols. Technological advances in treadmill and wheelchair roller design permit well established assessments of aerobic ${ }^{14,15}$ and anaerobic ${ }^{16}$ physiological parameters under standardised conditions. Recently, however, peak maximal-cardiorespiratory responses during 4 and 40 min field-based, continuous push tests in WR athletes were found to exceed those observed during a treadmill-based, graded exercise to exhaustionmaximal-exercise. ${ }^{17}$ Further, Leicht et al. ${ }^{15}$ reported a greater variability in $\mathrm{VO}_{2 \text { peak }}$ in athletes with tetraplegia (Co-efficient of variation (CV) 9.3\%) than paraplegia $(4.5 \%)$ or non-SCI $(3.3 \%)$ employing the same treadmill-based protocol. Wheelchair propulsion kinetics, including work per cycle (lower), and push frequencies (higher) are significantly altered during over-ground versus ergometer and treadmill-based propulsion at equivalent submaximal speeds $\left(4,6 \& 8 \mathrm{~km} \cdot \mathrm{h}^{-1}\right){ }^{18}$ No research has yet examined maximal push mechanics between laboratory and field-based scenarios. Anecdotal observations suggest WR athletes with tetraplegia adopt self-selected propulsion technique to compensate for impaired respiratory dynamics when performing high intensity activites. ${ }^{17}$ Subsequently, the performance of verification stages is recommended for 
178 the confirmation of peak cardiorespiratory responses, particularly in athletes with low 179 physical capacities or limited wheelchair propulsion experience. ${ }^{15}$

180 In the authors' experience When testing inexperienced athletes, both sub-optimal wheelchair configuration and a lack of wheelchair skills can significantly influence tests outcomes when testing inexperienced athletes. Improvements in physical performance over repeated testing sessions may result from habituation effects on propulsion technique and kinematics rather than improved cardiorespiratory capacity. Asynchronous, stationary arm crank ergometry $(\mathrm{ACE})$ is a more mechanically efficient than wheelchair propulsion, resulting in higher levels of peak power output $\left(\mathrm{PO}_{\text {peak } 2}\right.$ during $\operatorname{ACE}(\sim 30 \%$ higher $)$ with little difference in $\dot{\mathrm{V}} \mathrm{O}_{2 \text { peak. }}{ }^{19}$

ACE protocols have limited specificity to wheelchair performance and gripping aids are required when testing individuals with high spinal lesions. However, ACE protocols may be athlete in isolation from their equipment.

Extensive batteries of field-based tests have been validated for the assessment of anaerobic and manoeuvrability-related performance, including $20 \mathrm{~m}$ sprint and sport-specific protocols (see Goosey-Tolfrey and $\operatorname{Leicht}^{20}$ ), and show a strong association with functional classification. $^{21}$ - These are favoured by coaches due to ability to test large numbers of athletes with little specialised equipment and their direct representation of on-court performance. ${ }^{19}$ In contrast, the validity of continuous ${ }^{22,23}$ or shuttle-based ${ }^{24,25,26}$ field tests of aerobic capacity adapted from $\mathrm{AB}$ protocols remains inconclusive. To date, only Vinet et al. ${ }^{22}$ have performed direct comparisons between lab and field-based maximal cardiorespiratory responses during 199 wheelchair ergometry. No differences were observed between $\dot{\mathrm{V}} \mathrm{O}_{2 \text { peak }}$ measured during an 200 adapted Leger Boucherard test on 400m track and on a wheelchair ergometer, although only 201 moderate intra-class correlation coefficients (ICC) were reported. ${ }^{22}$ Elsewhere, only low to 
202 moderate correlations $(r=0.39-0.58)$ have been observed between final test score during a 203 multi-stage fitness test (MSFT) and $\dot{\mathrm{VO}}_{2 \text { peak }}$ identified during laboratory-based wheelchair 204 ergometry. ${ }^{25}$ Shuttle-based tests involve turning and acceleration and as such may under205 predict specific aerobic capacity due to the anaerobic contribution and influence of wheel speed on hand-rim contact at high speed. However, MSFT test scores demonstrate a strong relationship ( $r=0.80$ ) with wheelchair tennis skills as determined by players ranking and therefore may provide a functional indicator of wheelchair-user combination. ${ }^{24}$ Small standard errors of measurement have been confirmed for MSFT distance travelled ( $86 \mathrm{~m}, 95 \%$ CI: 59 to $157 \mathrm{~m})$ and peak HR $\left(2.4 \mathrm{~b} \cdot \mathrm{min}^{-1}, 95 \% \mathrm{CI}: 1.7\right.$ to 4.5$)$ suggesting that these variables can be measured reliably in a field-based setting. ${ }^{25}$ Recently, Weissland et al. ${ }^{23}$ reported higher $\dot{\mathrm{V}}_{2 \text { peak }}$ but no difference in final test score during a figure of 8 compared to an octagonal-based MSFT protocol in a group of WB athletes. Provided the adapted tests deliver reliable results that are sensitive to changes in physical performance, practitioners can identify the most suitable protocol for their individual needs. Due to the influence of chair configuration, tyre pressure and floor surface on wheelchair rolling resistance, the standardisation of such factors across observations is required where possible.

Currently, limited research has documented the physiological responses during actual or simulated competition in elite Paralympic athletes. Average $\dot{\mathrm{VO}}_{2}$ during both basketball and tennis competitions have been observed around the ventilatory threshold with average heart

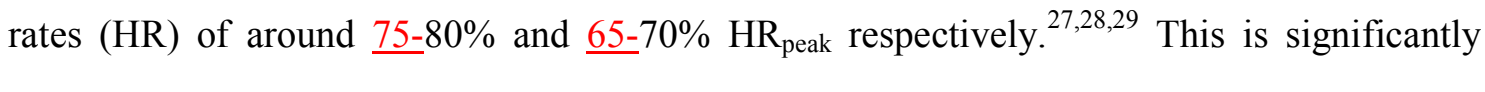
223 lower than intensities of continuous, endurance based wheelchair racing $\left(85 \% \dot{\mathrm{V}} \mathrm{O}_{2 \text { peak }}\right)$ and 224 nordic sit skiing competition $\left(82 \% \dot{\mathrm{VO}}_{2 \text { peak }}\right){ }^{28}$ A higher number and longer duration of breaks 225 during wheelchair tennis competition result in a greater work to rest ratio $(\sim 1: 5 ; 17 \%$ time 226 $\underline{\text { spent active }})^{29}$ compared to basketball $(\sim 1: 1) .{ }^{27}$ Figure 2 provides an example of Unpublished 
data from our research group displaying typical $\mathrm{HR}_{\text {peak }}$ and external-distances covered work completed during during the same duration of WR competition and game-specific training in players of two different impairments and classifications. groups is shown in Figure 2. The influence of impairment type on physiological responses and absolute intensities observed during on-court performance should be accounted for when benchmarking players both within and between classification groups. The Rreduced HR and active muscle mass in athletes with tetraplegia are associated with lower energy expenditures during WR $(248.5 \pm$ 69.4 kcal. $\left.\mathrm{h}^{-1}\right)$ compared to athletes with paraplegia performing WT $\left(325.8 \pm 73.0 \mathrm{kcal} . \mathrm{h}^{-1}\right)$ and WB $\left(374.8 \pm 127.1 \mathrm{kcal} . \mathrm{h}^{-1}\right){ }^{30}$

$\{[$ Insert Figure 2 here $]\}$

It has been shown that athletes cover distances that range between $3500-5000 \mathrm{~m}$ during WR and WB match-play. ${ }^{31,32,33}$ Around $28 \%$ of active basketball match-play is spent performing high intensity work, including sprinting or contesting for the ball, with $22 \%$ of activity above ventilatory threshold and 50\% resting. ${ }^{33}$ Positional requirements and player classification must be also taken into account when identifying an individual athlete's performance profile as role-specific demands can influence movement profiles. ${ }^{34}$ Recent data during WR matchplay found that the majority of time spent $(\sim 75 \%)$ was performing low intensity activities $(<50 \%$ peak speed) interspersed with short, frequent bouts of high intensity activity accounting for only $2-5 \%$ of total activity. ${ }^{35}$ Specifically, defensive players spend a significantly greater amount of time performing very low speed activities (blocking, trapping) compared to offensive players whilst performing a greater number of high-intensity activities $\left(\mathrm{n}=\sim 13\right.$ vs. $\sim 9$ respectively). ${ }^{35}$

In contrast to many linear endurance sports, no single physiological parameter determines performance outcome in court-based sports. In competitive WT match-play, Sindall et al. ${ }^{36}$ 
251 observed higher average speeds and greater distances covered in high versus low ranking 252 players. In addition, high ranked players also covered more distance at higher average HR 253 than their opponents. ${ }^{36}$ High ranking WR teams have been found to spend a greater time 254 within high $(>81-95 \%$ peak speed) $(2.9 \pm 1.6 \%)$ and very high $(>95 \%$ peak speed $)(0.7 \pm$ 255 $0.8 \%)$ speed zones compared to low $(1.5 \pm 1.1 \%$ and $0 \pm 0.4 \%)$ and mid-ranked teams $(2.0 \pm$ $1.3 \%$ and $0.3 \pm 0.5 \%$ ) across all classifications. ${ }^{35}$ Higher ranking teams also performed high intensity activities for greater distances and for a longer duration ${ }^{35}$, although opposition characteristics, including style of play and ranking, clearly influence indices of game intensity- As well as linear performance parameters, international-standard-WB players who represent national teams performed more frequent $(+7 \%)$ and longer duration $(+0.2 \mathrm{~s})$ rotational activities and fewer braking activities compared to club level counterparts during simulated match-play. ${ }^{37}$ - national level counterparts ${ }^{33}$-Consequently, techniques for profiling linear and rotational performance are important to understand sport-specific movement profiles and prescribe training intensities to match or exceed the demands of the competition environment.

266 The indoor tracking system (ITS), as used by Rhodes et $\mathrm{al}^{35}$, has been proved to be a valid and reliable tool for the assessment of distance/speed during a range of tasks specific to the wheelchair court sports. ${ }^{38}$ Importantly, the ITS has shown good reliability reliable even at maximal speeds $\left(>4 \mathrm{~m} \cdot \mathrm{s}^{-1}\right)$, where random errors of $<0.10 \mathrm{~m} \cdot \mathrm{s}^{-1}$, with $<2 \% \mathrm{CV}$ were observed. ${ }^{38}$ Unfortunately, from a practical perspective, the ITS requires considerable setup/calibration time and to date no acceleration or angular velocity data has been reported using this system. Image-based processing techniques have also previously been employed 273 for the quantification of WR match-play movement. ${ }^{32}$ However, these techniques are heavily reliant on manual tracking digitisation which introduces accuracy and reliability issues and are not suitable if athletes/coaches require timely feedback post training or competition. 
276 Devices (e.g., wheel mounted magnetic -reed-switch devices) originally designed to measure 277 the daily life activity patterns of wheelchair uses have recently been assessed for their 278 suitability in sporting environments. ${ }^{36,39}$ These compact devices attach near the axle of the 279 main wheels and, powered by long life batteries, enable data to be collected and stored over 280 extended periods ( $\sim 3$ months). ${ }^{39}$ Yet, substantial errors in measurement reliability (19.9\% CV) 281 have been reported when determining peak speed, resulting in large random errors in time 282 and distance spent in speed zones relative speed zones. ${ }^{39}$ Therefore, the interest in measurement tools continues, with wireless inertial measurement units (IMU) reported to be reliable for assessing wheelchair kinematics once corrected for wheel skidding during vigorous activity. ${ }^{40}$ Average test outcomes for linear speed (ICCs>.90) and rotational speed (ICCs>.99) showed high correlations between IMU and a 'gold-standard' 24 camera optical motion analysis system. ${ }^{40}$ More research is required to validate the use of IMU's during competition match-play rather than standardised environments and refine adaptations to apply/remove devices from the sports wheelchair in a timely manner.

\section{Interventions to enhance physical capacity and performance}

When initiating interventions to enhance physical performance, consideration must be made to both an athlete's impairment-specific physiological responses and sport-specific movement and energetic demands. The accurate quantification and longitudinal monitoring of prescribed training load (TL) is essential to provide a scientific explanation for changes in performance and manage illness/injury risk. As well as enhancing physical capacities, interventions also focus on the integration of the athlete and their equipment as well as techniques for limiting environmental influence on performance (Figure 1). Recent interest has been paid to the nutritional supplement habits of Paralympic athletes, with recommendations made for a greater education for athletes on appropriate information sources and dosage requirements. ${ }^{5}$ 
301

302

303

304

305

on endurance and sprint-based performance in wheelchair court-sport athletes, respectively. However, a wider discussion regarding the influence of impairment type on the efficacy of nutritional supplements, including side-effects (e.g., increased spasms), optimising fluid intake (e.g., preventing dehydration and urinary infection risk) and impaired absorption rates (e.g., reduced gastric motility), is beyond the scope of this review. $\frac{43}{}$ The subsequent sections will discuss literature regarding training prescription practices, adaptations to the wheelchair/user interface and cooling strategies to enhance physical performance.

\section{Training prescription and monitoring}

The quest for optimal performance requires practitioners to continuously balance strategies to support and improve physical capacities alongside coach-led on-court technical/tactical training demands. Remaining function can be trained through programs that involve specific on-court and over-ground wheelchair propulsion, non-specific arm-crank ergometer training, hand cycling and resistance training (Table 1). These must be balanced with technical and tactical requirements prescribed by coaches. Due to the relatively small muscle mass of the upper limb and the high mobility but low stability of the shoulder girdle, wheelchair propulsion is a mechanically inefficient exercise modality. $\frac{19}{}$ The associated large load and the instability of the shoulder complex provide a risk factor for chronic over-use injuries in manual wheelchair users. ${ }^{4}$ Interventions should first ensure the robustness of athletes shoulder by re-enforcing positive functional movement patterns and symmetry in scapula kinematics through strength (e.g., elastic bands) and coordination (e.g., visual stimuli) exercises. ${ }^{44}$ In athletes with CP passive stretching of the shoulder is recommended to provide proprioceptive training of joint movement and increase joint range of motion.

Several studies conducted with elite wheelchair athletes have reported favourable changes in functional performance ${ }^{3,45,46}$ or body composition ${ }^{46,47}$ when following a periodised program 
325 during a competitive season. To the author's knowledge, only two studies have intervened

326 with specific strength and resistance training programmes of wheelchair athletes. ${ }^{44,48}$

327 Turbanski and Schmidtbleicher ${ }^{48}$ found that wheelchair athletes demonstrated significant

328 improvements in strength and power as a result of 8 weeks resistance training which

329 incorporated heavy bench press exercises. It was noted that the velocity and acceleration

330 associated improvements of the bench press throw contributed to a $6.2 \%$ improvement in

$33110 \mathrm{~m}$ sprinting performance. ${ }^{48}$ Moreover, while no direct strength improvements were noted

332 following the 3 month elastic band and visual coordination training of Bergamini et al. ${ }^{44}$

333 significant improvements in wheelchair propulsion kinematics (e.g. reduced asymmetry)

334 were noted. No studies have yet differentiated between responses in SCI athletes or those

335 with limb deficiency or neurological impairments.

$336\{[$ Insert Table 1 here $]\}$

337 The outcome of any training intervention is the consequence of both the work completed 338 ('External load' = distance, speed, power) and the resultant stress on the athlete's 339 physiological systems ('Internal load' $=\dot{\mathrm{V}} \mathrm{O}_{2}, \mathrm{HR}$ ). On-court training in the team sports is 340 frequently prescribed on a squad-basis to develop sport-specific, technical and tactical 341 competences. The large heterogeneity in athlete impairment and conditioning within a squad 342 may result in a range of internal TL responses to the same dose of external load (see Figure 343 2). The use of ratings of perceived exertion (RPE) is preferable to HR methods, the 344 intermittent nature of court sports mean HR may not be directly associated with external 345 work performed, including high intensity accelerations and decelerations. ${ }^{49}$ Further, 346 wheelchair athletes with a high spinal lesion may have a blunted HR response, whilst RPE 347 displays a linear response with $\mathrm{VO}_{2} \cdot{ }^{50}$ Leicht et al. ${ }^{14}$ reported the same RPE responses at 348 fixed relative exercise intensities across athletes with tetraplegia, paraplegia and non-SCI. 
349 Therefore RPE may be considered a useful tool for the prescription and monitoring of athlete 350 training. While the use of session RPE provides a valid alternative to HR-based methods for 351 assessing distance covered and low to moderate intensity activity, the intra-individual 352 relationships between external TL measures and session RPE should be assessed for each 353 athlete prior to performing any systematic longitudinal monitoring. ${ }^{50}$ It is recommended that 354 external TL data are considered within the context of the training environment and a 355 combination of internal and external load employed to accurately quantify across training 356 modes. ${ }^{50}$

357 Respiratory muscle training and cardiorespiratory function

358 As mentioned earlier, persons with a SCI suffer from a lesion-level dependent impairment in 359 respiratory muscle function and cardiovascular function. Both can contribute to the delivery of oxygenated blood to active muscles during upper limb exercise. Consequently, there has been an interest in establishing effective respiratory training programmes or cardiorespiratory aids (e.g. use of abdominal binders or strapping) to support aerobic capacity in wheelchair athletes. Previously, only positive indicators of quality of life (i.e. reduced scores of breathlessness) had been found following six weeks of inspiratory muscle training (IMT) in trained WB players of mixed physical disabilities. ${ }^{51}$ Elsewhere, more encouraging improvements have been reported by West and co-workers ${ }^{52}$ who examined a more homogeneous group of athletes (i.e. highly trained WR players with tetraplegia) and found a $15 \%$ increase in $\mathrm{PO}_{\text {peak }}$ following a 6 week period of IMT training. Accordingly, IMT may provide a useful adjunct to training in this population but current literature is inconclusive.

370 Other physiological interventions aimed at augmenting cardiorespiratory function in athletes

371 with tetraplegia include the use of compression socks ${ }^{53}$ and abdominal binders ${ }^{54}$ during acute 372 exercise. Both may act to enhance venous return and consequently improve ventricular filling 
373 pressure, stroke volume and cardiac performance in those with compromised vascular

374 function. ${ }^{53,54}$ Lower limb compression may be associated with an augmentation of upper limb

375 blood flow and increased submaximal exercise performance. ${ }^{53}$ As well as providing stability

376 around the trunk, the use of abdominal binders has been associated with: i) reductions in

377 minute ventilation and blood lactate accumulation during submaximal exercise; and ii)

378 improvements in acceleration/ deceleration profiles and distance covered during a repeated

379 maximal 4-min push. ${ }^{54}$

$380\{[$ Insert Table 2 here $]\}$

381

382

\section{Equipment/User interface}

The athlete and their individualised sports wheelchair must be considered as 'one'; becoming the 'wheelchair-user interface'. The configuration of a wheelchair, including alterations to hand rim diameter, tire pressure, wheel size, camber, seat height, has a substantial influence on performance. While some aspects of configuration may be advantageous for one aspect of sport (e.g., increasing wheel camber to increase manoeuvrability), they may impair other aspects of performance (e.g, this may reduce linear speed due to increase rolling resistance). ${ }^{55}$ Despite the abundance of research with an ergonomic interest on wheelchair configuration, very few studies have utilised wheelchair games players and measured sports performance specific outcomes of functional capacity (see Mason et al. ${ }^{55}$ ).

Trunk function has been identified as a central component determining sports performance (e.g., wheelchair sports classification). ${ }^{12}$ Reducing the contribution of trunk to sprinting performance via manipulations in seat angles has been shown to significantly reduce acceleration and sprinting capability. ${ }^{12}$ The combined impact of strapping/ seating position and the individual fit to the sports wheelchair must therefore be considered collectively whenever possible to maximise trunk contribution to performance (see Table 2). 
397 Interventions of the interface between user and equipment have also been sought, including 398 the use of neoprene belts to increase range-of-reach by stabilizing the chest to the wheelchair 399 using a belt. ${ }^{56}$ Elsewhere, Mason et al. ${ }^{57}$ found glove type to impact sprint measures such as 400 acceleration and $15 \mathrm{~m}$ sprint times improving the hand rim user interface. However, a large 401 number of individual glove types are available and elite athletes seem to perform best in their 402 custom-made gloves. ${ }^{57}$

\section{Cooling strategies}

404 The scientific literature is well versed regarding the problems of exercise in the heat, the 405 effects of dehydration and the benefits of acclimatisation for the AB athlete. However, there 406 are a variety number of considerations for athletes with disabilities exercising in the heat 407 where thermo-regulatory impairment increases the risk from heat-related illness. ${ }^{10,11}$ There 408 have been a variety of studies examining the effects of pre-cooling prior to exercise in 409 athletes with tetraplegia ${ }^{58}$ and as well as those aiming to reduce heat storage during exercise 410 in athletes with paraplegia who compete outdoors in events such as wheelchair tennis 3,59 411 which may last between 1-3 h. ${ }^{36}$ These selected studies shown in Table 2 replicated the 412 exercise of a similar duration or intensity of that undertaken in wheelchair tennis or rugby. In 413 brief, key findings suggest that i) wearing an ice vest during prior to intermittent sprint 414 exercise both reduces thermal strain and enhances performance and ii) hand cooling is 415 effective as a cooling aid. Wearing an ice vest during on-court training may not attenuate the 416 rise in core temperature in athletes with paraplegia and tetraplegia, although the influence on 417 performance remains equivocal ${ }^{60}$-Yet, The practicality of cooling must be considered as 418 wheelchair athletes would not wish to experience feelings of numbness of the hands when

419 hand dexterity in court sports is of paramount importance. Prior heat acclimation protocols 420 421 may provide one method of improving thermoregulatory stability and reducing heat stress $\underline{\text { when competing in challenging environments for prolonged periods e.g. tennis competition. }{ }^{61}}$ 


\section{Practical applications}

423 The present brief review has outlined current practical perspectives and scientific literature 424 regarding the profiling and enhancement of physical performance in wheelchair-court sports.

425 A range of physical impairments demand a fully individualised approach to supporting 426 wheelchair athletes. However, a number of key principles exist which provide the foundation 427 upon which bespoke sport science and medicine programmes can be implemented.

428 - An understanding of the individual wheelchair athlete is vital, including a full medical 429 diagnosis of physical impairment, screening of current functional movement pattern $430 \quad$ and previous illness/injury history.

- Profiling protocols must show good reliability and demonstrate specificity to the movement or energetic demands of competition. The battery of protocols available to practitioners will be dependent on available resource (lab vs. field assessments), the experience of athletes being profiled (novice vs. experienced wheelchair user) and contact time available with athletes.

- A range of technologies are available for examining the movement and physiological demands of performance, including HR monitoring, motion capture, ITS and IMU. However, the limitations of each technique must be acknowledged and considered when supporting coaches in the training and competition environment.

- A multi-disciplinary approach to the preparation and assessment of interventions aimed at enhancing physical performance is essential. Interventions may increase one element of performance (linear speed) but be detrimental to other parameters of athlete health or performance.

\section{Conclusion}


445 Despite the growing interest in Paralympic sport, the evidence-base for supporting wheelchair 446 sport performance remains limited. Current practice is often based on theory adapted from $447 \mathrm{AB}$ guidelines, with a heavy reliance on anecdotal evidence and practitioner experience. 448 Where possible this practitioner experience should be supplemented with impairment and 449 sport-specific applied research. The optimisation of wheelchair sport performance requires a 450 multi-disciplinary approach based on the individual requirements of each athlete in their 451 sporting environment.

452 
Table 1 Longitudinal training strategies designed to improve the physical capacity of competitive wheelchair games players

454

\begin{tabular}{|c|c|c|c|c|c|c|}
\hline Author & Sport & $\begin{array}{l}\text { Number/sex } \\
\text { (impairment)/ } \\
\text { playing } \\
\text { standard }\end{array}$ & $\begin{array}{l}\text { Age } \\
\text { (yr.) } \\
\text { Mean } \\
\pm \text { SD } \\
\end{array}$ & Training methods & $\begin{array}{l}\text { Measures of physical } \\
\text { capacity and body } \\
\text { composition }\end{array}$ & Outcomes \\
\hline \multicolumn{7}{|c|}{ Usual Training Practices } \\
\hline Goosey-Tolfrey ${ }^{45}$ & Basketball & $\begin{array}{l}12 \text { Male, Mixed } \\
(1.0-4.0 \mathrm{IWBF}) \\
\text { International }\end{array}$ & $30.5 \pm 4.5$ & $\begin{array}{l}\text { Three year longitudinal } \\
\text { observation. Twenty hours of } \\
\text { physical and skill training per } \\
\text { week. Sport-specific game play } \\
\text { and club training }\end{array}$ & $\begin{array}{l}\text { Peak aerobic capacity and } \\
\text { sprint performance using } \\
\text { treadmill and wheelchair } \\
\text { ergometer. Athletes tested } \\
\text { in their own sports } \\
\text { wheelchairs }\end{array}$ & $\begin{array}{l}\text { Aerobic capacity improved by } \\
6.8 \% \text { while all other fitness } \\
\text { prerequisites, including sprint } \\
\text { performance, were maintained }\end{array}$ \\
\hline Iturricastillo et al. ${ }^{46}$ & Basketball & $\begin{array}{l}8 \text { Male, Mixed } \\
1^{\text {st }} \text { Division } \\
\text { Club }\end{array}$ & $26.5 \pm 2.9$ & $\begin{array}{l}\text { Longitudinal observation across } \\
\text { one competitive club season (of } \\
16 \text { matches and training twice per } \\
\text { week). Training sessions included } \\
1 \mathrm{hr} \text { of technical and tactical } \\
\text { drills. Each session always ended } \\
\text { with real game situations }\end{array}$ & $\begin{array}{l}\text { Handgrip, body } \\
\text { composition (skinfold; } \\
\text { triceps, subscapular, } \\
\underline{\text { suprailiac and abdominal), }} \\
\text { medicine ball throw, on- } \\
\text { court sprinting ( } 5 \text { and } 10 \\
20 \text { m sprints) and } \\
\text { completion of the Yo-Yo } \\
\text { level } 1 \text { test of } 10 \text { m. } \\
\text { Athletes tested in their } \\
\text { own sports wheelchairs }\end{array}$ & $\begin{array}{l}\text { Improvements in body } \\
\text { composition (decreased fat mass } \\
\text { of upper limb) and physical } \\
\text { performance, particularly in } \\
\text { acceleration over } 5 \text { and } 20 \mathrm{~m} \\
\text { sprint with the ball, handgrip } \\
\text { strength and the total distance } \\
\text { covered in the Yo-Yo level } 1 \\
\text { endurance test. No differences } \\
\text { were observed in acceleration } \\
\text { capacity without the ball, change } \\
\text { of direction ability or explosive } \\
\text { strength. }\end{array}$ \\
\hline Gorla et al. ${ }^{47}$ & Rugby & $\begin{array}{l}13 \text { Male, TP } \\
1^{\text {st }} \text { Division } \\
\text { Club }\end{array}$ & $26.6 \pm 6.0$ & $\begin{array}{l}\text { Longitudinal observation across } \\
\text { one season ( } 8.1 \pm 2.5 \text { months). } \\
\text { Four sessions per week of aerobic } \\
\text { and anaerobic sport specific (inc. } \\
\text { technical and tactical) aspects of } \\
\text { wheelchair rugby }\end{array}$ & $\begin{array}{l}\text { Body composition using } \\
\text { dual-energy x-ray } \\
\text { absorptiometry (DXA) }\end{array}$ & $\begin{array}{l}\text { Regular wheelchair rugby } \\
\text { training results in an increase in } \\
\text { lean mass and decreased total } \\
\text { body fat mass. }\end{array}$ \\
\hline $\begin{array}{l}\text { Diaper and Goosey- } \\
\text { Tolfrey }^{3}\end{array}$ & Tennis & $\begin{array}{l}1 \text { Female, PP } \\
\text { (L1) } \\
\text { International }\end{array}$ & 33 & $\begin{array}{l}2 \text { years observational study. } \\
\text { Twenty hours of physical and } \\
\text { skill training per week. Sport- }\end{array}$ & $\begin{array}{l}\text { Aerobic capacity and } \\
\text { repeated sprint } \\
\text { performance }(10 \mathrm{~s} \text { x } 10\end{array}$ & $\begin{array}{l}\text { Aerobic capacity reduced by } \\
21 \% \text {, yet the submaximal } \\
\text { physiological variables such as }\end{array}$ \\
\hline
\end{tabular}




\begin{tabular}{|c|c|c|c|c|c|c|}
\hline & & & & $\begin{array}{l}\text { specific game play and club } \\
\text { training }\end{array}$ & $\begin{array}{l}\text { sprints with } 30 \text { s recovery) } \\
\text { using a wheelchair } \\
\text { ergometer. Athlete tested } \\
\text { in their own tennis } \\
\text { wheelchair }\end{array}$ & $\begin{array}{l}\text { lactate profile and pushing } \\
\text { economy improved. } \\
\text { Maintenance of peak speed and } \\
\text { improvement found in the } \\
\text { fatigue profile across the } \\
\text { repeated sprint performance }\end{array}$ \\
\hline \multicolumn{7}{|c|}{ Strength and Conditioning Training } \\
\hline Bergamini et al. ${ }^{44}$ & Basketball & $\begin{array}{l}10 \text { Male, } 2 \\
\text { Female } \\
\text { Mixed } \\
\text { Junior Club }\end{array}$ & $17.1 \pm 2.7$ & $\begin{array}{l}\mathrm{n}=6 \text { control group and } \mathrm{n}=6 \\
\text { training group (TG). Both groups } \\
\text { undertook, } 2 \text { times a week, } 90 \\
\text { min sessions aimed to improve } \\
\text { wheelchair propulsion, wheelchair } \\
\text { manoeuvrability and ball handling } \\
\text { skills. The TG also completed } \\
\text { twice a week for three months } \\
\text { strength (elastic bands) and } \\
\text { coordination (inc. visual stimuli) } \\
\text { exercises lasting } 30-35 \text { mins }\end{array}$ & $\begin{array}{l}20 \text { m sprint test. } \\
\text { Wearable inertial } \\
\text { measurement units (IMUs) } \\
\text { devices to measure } \\
\text { biomechanical parameters } \\
\text { in wheelchair sports }\end{array}$ & $\begin{array}{l}\text { No improvement in } 20 \mathrm{~m} \text { sprint } \\
\text { after the TG. Athletes modified } \\
\text { their propulsion technique } \\
\text { following training by increasing } \\
\text { the push cycle frequency, the } \\
\text { force expressed to accelerate } \\
\text { their wheelchair and adopting a } \\
\text { more symmetrical pushing mode }\end{array}$ \\
\hline $\begin{array}{l}\text { Turbanski and } \\
\text { Schmidtbleicher }\end{array}$ & $\begin{array}{l}\text { Basketball } \\
\text { and Rugby }\end{array}$ & $\begin{array}{l}8 \mathrm{Male} \\
8 \mathrm{PP} / 2 \mathrm{TP} \\
1^{\text {st }} \text { and } 2^{\text {nd }} \\
\text { Division }\end{array}$ & $\begin{array}{l}33.2 \\
\pm 10.6\end{array}$ & $\begin{array}{l}\text { Eight week resistive training } \\
\text { regimen. Exercises were } \\
\text { performed twice per week with } \\
\text { program variables of } 70 \text { to } 85 \% \\
\text { intensity of } 1 \text { repetition maximum } \\
\text { (1RM) and } 5 \text { sets not exceeding } \\
12 \text { repetitions. }\end{array}$ & $\begin{array}{l}10 \mathrm{~m} \text { sprint test. Strength } \\
\text { and power measures } \\
\text { included the bench throw - } \\
\text { maximal velocity, maximal } \\
\text { acceleration, and time } \\
\text { intervals representing the } \\
\text { initial acceleration ( } \mathrm{t} 1 \text { and } \\
\text { t2) of the barbell. Maximal } \\
\text { strength (Fmax) and } \\
\text { maximal } \\
\text { rate of force development } \\
\text { (MRFD) was measured in } \\
\text { the static condition. } \\
\text { Dynamic bench press } 1 \mathrm{RM} \\
\text { and strength endurance } \\
\text { (SE) were also measured. }\end{array}$ & $\begin{array}{l}\text { Improvements were noted for all } \\
\text { tests. With improvements in } 10 \\
\mathrm{~m} \text { sprints of } 1.8 \% \text { and as large as } \\
39.3 \% \text { in the } 1 \mathrm{RM}(\mathrm{kg})\end{array}$ \\
\hline \multicolumn{7}{|c|}{ Respiratory muscle training } \\
\hline Goosey-Tolfrey et al. ${ }^{5}$ & Basketball & $\begin{array}{l}16 \text { Male, Mixed } \\
\text { (1.0-3.0 IWBF) } \\
1^{\text {st }} \text { Division }\end{array}$ & NS & $\begin{array}{l}\text { Six weeks inspiratory muscle } \\
\text { training (IMT) - Two Groups } \\
\text { IMT group - } 30 \text { dynamic breaths }\end{array}$ & $\begin{array}{l}\text { Repetitive sprint test } \\
\text { (RST) comprised of } 15 \mathrm{x} \\
20 \mathrm{~m} \text { sprints. Total test }\end{array}$ & $\begin{array}{l}\text { IMT - MIP and MEP improved } \\
\text { (17\% and } 23 \% \text {, respectively). } \\
\text { Sham-IMT also resulted in } 23 \%\end{array}$ \\
\hline
\end{tabular}




\begin{tabular}{lll} 
& Club \\
& \\
& \\
& \\
\hline West et al. $^{52}$ & Rugby & 10 TP 9 Male 29.2 \pm 5.5 \\
& and 1 Female \\
& (C4-C5 COM to \\
& C6-C7 INC) \\
& International
\end{tabular}

Club

performed by the twice daily at a

resistance equivalent to $50 \%$

maximum inspiratory pressure

(MIP).

sham-IMT group - 60 slow

breaths performed once a day at $15 \%$ MIP

breaths twice daily

IMT group $(\mathrm{n}=5)$ or placebo

$(\mathrm{n}=5)$

Internationa

Note. PP - Paraplegic; TP - Tetraplegic; NS - not stated; ${ }^{*}$ - hand timing time and recovery time were recorded. HR and post blood lactate concentration measured.

Respiratory muscle

strength; (MIP and MEP)

Incremental arm crank

and 33\% improvements. There were no significant changes in pulmonary function at rest and any of the performance

parameters associated with the RST

\section{exercise test to determine}

peak aerobic work rate and

diaphragm thickness
IMT resulted in significant increase by $8 \mathrm{~W}(+15 \%)$ in incremental test peak aerobic work rate. IMT also showed significant increase in diaphragm thickness vs. placebo 
476 Table 2 Studies examining influence of wheelchair/user interface, compression garments and cooling and respiratory interventions on sport477 specific performance of trained wheelchair games players.

\begin{tabular}{|c|c|c|c|c|c|c|}
\hline Author & Sport & $\begin{array}{l}\text { Number/ Sex } \\
\text { (Impairment) }\end{array}$ & Method & & Modality/ Protocol & Performance Gains \\
\hline \multicolumn{7}{|c|}{$\begin{array}{l}\text { STRATEGIES } \\
\text { Wheelchair-user interface }\end{array}$} \\
\hline Curtis et al. ${ }^{56}$ & Basketball & $\begin{array}{l}7 \text { Mixed, } 6 \text { Male/ } \\
1 \text { Female } \\
(1.0-2.0 \mathrm{IWBF})\end{array}$ & $\begin{array}{l}\text { Strapping } \\
\text { techniques }\end{array}$ & $\begin{array}{l}\text { Without a belt, } \\
\text { with a neoprene } \\
\text { chest belt and } \\
\text { with a webbing } \\
\text { thigh belt }\end{array}$ & $\begin{array}{l}\text { Participants were in a static seated } \\
\text { position. They held a basketball in } \\
\text { either the transverse or sagittal } \\
\text { plane and reached within the } \\
\text { limits of their stability. The area } \\
\text { circumscribed by each } \\
\text { participant's functional reach was } \\
\text { processed using the Motion } \\
\text { Analysis Expert Vision Flextrak } \\
\text { program }\end{array}$ & $\begin{array}{l}\text { Sagittal plane - high and low } \\
\text { thoracic level athletes increased } \\
\text { the area of their functional reach } \\
\text { with the chest belt when compared } \\
\text { with the thigh or no-belt } \\
\text { condition. However, in the } \\
\text { transverse plane, only lower level } \\
\text { thoracic paraplegics (T8 to L1) } \\
\text { benefited from chest strapping, } \\
\text { increasing the area of their } \\
\text { functional reach by a mean of } \\
24 \%\end{array}$ \\
\hline Mason et al. ${ }^{57}$ & Rugby & $\begin{array}{l}10 \mathrm{TP}, \text { Male }-9 \\
\text { Male/ } 1 \text { Female }\end{array}$ & Gloves & $\begin{array}{l}\text { Own, American } \\
\text { football, building } \\
\text { and new } \\
\text { prototype gloves }\end{array}$ & $\begin{array}{l}\text { Overground propulsion (indoor) - } \\
\text { Own court sports chair. Tests } \\
\text { involved } 3 \text { drills that measured } \\
\text { acceleration, braking and } \\
\text { sprinting }\end{array}$ & $\begin{array}{l}\text { Better acceleration and sprint } \\
\text { performance wearing own gloves. } \\
\text { Subjective data also identified that } \\
\text { players favoured their own gloves }\end{array}$ \\
\hline \multicolumn{7}{|c|}{$\begin{array}{l}\text { STRATEGIES } \\
\text { Cardiovascular hemodynamics }\end{array}$} \\
\hline Vaile et al. ${ }^{53}$ & Rugby & $\begin{array}{l}10 \text { TP Male } \\
\text { (C5-C6 COM - } \\
\text { C7 INC) }\end{array}$ & $\begin{array}{l}\text { Compression } \\
\text { Socks (COMP } \underline{\mathrm{CS}})\end{array}$ & $\begin{array}{l}\text { COMP CS worn } \\
\text { during exercise } \\
\text { vs. control (CON) }\end{array}$ & $\begin{array}{l}\text { Overground propulsion (indoor) - } \\
\text { Own court sports chair. } 4 \text { x } 8 \text { min } \\
\text { submaximal exercise with full } \\
\text { court sprint }\end{array}$ & $\begin{array}{l}\text { Significant average lap time was } \\
\text { better maintained in COMP } \underline{\mathrm{CS}}\end{array}$ \\
\hline West et al. ${ }^{54}$ & Rugby & $\begin{array}{l}10 \mathrm{TP}-8 \text { Male } \\
\text { and } 2 \text { Female } \\
(\mathrm{C} 5-\mathrm{C} 7 \mathrm{COM})\end{array}$ & Abdominal binder & $\begin{array}{l}\text { Binding worn } \\
\text { during } 17 \text { field- } \\
\text { based } \\
\text { performance } \\
\text { measures vs. } \\
\text { control (CON) }\end{array}$ & $\begin{array}{l}\text { Wheelchair propulsion (indoor) - } \\
\text { Own court sports chair. } \\
\text { Tests included measures of } \\
\text { agility, acceleration/ deceleration, } \\
\text { repeated sprint, submaximal } \\
\text { efficiency, Wingate test and } \\
\text { repeated } 4 \text { min push efforts }\end{array}$ & $\begin{array}{l}\text { Six tests demonstrated } \\
\text { performance gains with binding. } \\
\text { Improvements were noted with the } \\
\text { acceleration/ deceleration profiles } \\
\text { and distance covered during the } \\
\text { repeated } 4 \text { min push. Reductions } \\
\text { in minute ventilation during }\end{array}$ \\
\hline
\end{tabular}




\section{Cooling Interventions}

Goosey-Tolfrey et Tennis al. ${ }^{5}$

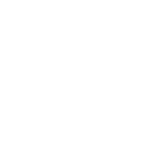

\section{Diaper and}

Goosey-Tolfrey

Tennis

30 min wearing an

\begin{tabular}{|c|c|c|c|}
\hline Webbern et at. ${ }^{54}$ & $\begin{array}{l}\text { Tennis \& } \\
\text { Rugby }\end{array}$ & $\begin{array}{l}8 \text { TP Male } \\
\text { (C5/C6-C6/C7, } 2 \\
\text { INC) }\end{array}$ & Ice vest \\
\hline Webborn et al. ${ }^{58}$ & $\begin{array}{l}\text { Tennis \& } \\
\text { Rugby }\end{array}$ & $\begin{array}{l}8 \text { TP Male } \\
\text { (C5/C6-C6/C7, } \\
\underline{n}=2 \text { INC) }\end{array}$ & Ice vest \\
\hline
\end{tabular}

1 PP Female (L1)

Cooling Garments

Precooling for

ice vest followed

by head/neck

cooling vs. CON

during exercise

2 TP Male, 5 Hand cooling $\mathrm{HC}$ vs. $\mathrm{CON}$

Male/ 1 Female (HC) versus non- following 60-min

(Open tennis cooling control steady-state

exercise prior to

$1 \mathrm{~km}$ time-trial

20 min before

start of exercise

(PRE), during

exereise (DUR)

$\forall$. CON

$20 \mathrm{~min}$ before

start of exercise

(PRE), during

exercise

(DUREXE) vs.

CON
Wheelchair ergometer - own

court sports chair. 60-min

exercise consisting of five 10-min

blocks at $50 \%$ peak power output,

separated by 2 min passive rest at

$\underline{30.8^{\circ} \pm 0.2^{\circ} \text { and } 60.6 \% \pm 0.2 \%}$

relative humidity for both

conditions.

Wheelchair ergometer - own

tennis sports chair. $60 \mathrm{~min}$

intermittent sprint protocol at 30.4

$\pm 0.6^{\circ}, 54 \pm 3.8 \%$ relative

humidity for two conditions

Arm crank Intermittent Sprint

Protocol (ISP) 28 min duration

ISP consisting of 10 s of passive

rest, a 5 s maximal sprint

followed by 105 s of active

recovery at $35 \%$ aerobic capacity

Arm crank Intermittent Sprin

Protocol (ISP) - up to thirty 2-min

periods consisting of $10 \mathrm{~s}$ of

passive rest, a 5-s maximal sprint

followed by $105 \mathrm{~s}$ of active

recovery at $35 \%$ aerobic capacity submaximal test as well as blood lactate accumulation and ratings of perceived exertion (RPE) during the second set of the repeated 4 min push test

$1 \mathrm{~km}$ time-trial performance reduced by $20.5 \mathrm{~s}$ after $\mathrm{HC}$

Mean speed was maintained as a result of cooling across the $5 \times 10$ min blocks of exercise

The cooling strategies appeared to lower the perceived exertion of the exercise, which may translate to improved function capacity

PRE - 4 athletes completed the full duration, with all athletes completing 16 sprints $(32 \mathrm{~min}$ ) All athletes in DUR EXE were able to sprint longer than the other conditions, completing 22 sprints (44 min). Mean exercise duration was improved by both PRE and DUREXE when compared with CON. The cooling strategies also 
appeared to lower the perceived exertion of the exercise, which may translate to improved function capacity

479 Note. IWBF - International Wheelchair Basketball Federation; C - cervical; SB - spina bifida; SCI - spinal cord injury; TP - tetraplegic; PPPARA - paraplegic; 480 INC - incomplete; COM - complete; FHF _ French Handisport Federation. 


\section{References}

1. Tweedy SM, Vanlandewijck YC. International Paralympic Committee position standbackground and scientific principles of classification in Paralympic sport. Br J Sports Med. 2011;45:259-269.

2. Burkett B. Technology in Paralympic sport: Performance enhancement or essential for performance. Br J Sports Med. 2010;44:215-220.

3. Diaper N, Goosey-Tolfrey VL. A physiological case study of a Paralympic wheelchair tennis player: Reflective practise. J Sport Sci Med. 2009;8:300-307.

4. Webborn N, Van de Vliet P. Paralympic medicine. Lancet. 2012;379:65-71.

5. Graham-Paulson TS, Perret C, Smith B, Crosland J, Goosey-Tolfrey VL. Nutritional supplement habits of athletes with an impairment and their sources of information. Int J Sport Nut Exerc Met. 2015;25(4): 387-395.

6. Tweedy S, Diaper N. Introduction to wheelchair sport. In: Goosey-Tolfrey VL, editor. Wheelchair sport. $1^{\text {st }}$ ed. Hum Kin, Champaign (IL), 2010;3-27.

7. Haisma JA, Woude van der LHV, Stam, HJ, Bergen MP, Sluis TAR, Bussman JBJ. Physical capacity in wheelchair-dependent persons with a spinal cord injury: A critical review of the literature. Spinal Cord. 2006;44:642-652.

8. Theisen D. Cardiovascular determinants of exercise capacity in the Paralympic athlete with spinal cord injury. Exp Physiol. 2012;97(3):319-324.

9. West CR, Romer LM and Krassioukov A. Autonomic function and exercise performance in elite athletes with cervical spinal cord injury. Med Sci Sports Exerc. 2013;45(2):261-267.

10. Webborn N, Price MJ, Castle, PC, Goosey-Tolfrey VL. Cooling strategies improve intermittent sprint performance in the heat of athletes with tetraplegia. Br J Sports Med. 2010; 44(6):455-460.

11. Griggs KE, Price MJ, Goosey-Tolfrey VL. Cooling athletes with a spinal cord injury. Sports Med. 2015;45(1): 9-21.

12. Vanlandewijck YC, Verellen J, Tweedy S. Towards an evidence-based classification in wheelchair sports: impact of seating position on wheelchair acceleration. J Sports Sci. 2011;29(10):1089-1096.

13. Lennon N, Thorpe D, Balemans AC, Fragala-Pinkham M, O’Niel, M, Bjornson K, Boyd R, Dallmeijer AJ. The clinimetric properties of aerobic and anaerobic fitness measures in adults with cerebral palsy: A systematic review of the literature. Res Dev Disibil. 2015;45:316-328.

14. Leicht CA, Bishop NC, Goosey-Tolfrey VL. Submaximal exercise responses in tetraplegic, paraplegic and non-spinal cord injured elite wheelchair athletes. Scand J Med Sci Sports. 2012;22(6):729-736.

15. Leicht, CA, Tolfey, K, Lenton JP. Bishop NC, Goosey-Tolfrey VL. The verification phase and reliability of physiological parameters in peak testing of elite wheelchair athletes. Eur $J$ Appl Physiol. 2013:113(1):201-209.

16. Hutzler Y. Anaerobic fitness testing of wheelchair users. Sports Med. 1998;25(2):101-113.

17. West CR, Leicht CA, Goosey-Tolfrey VL, Romer LM. Perspective: Does laboratory-based maximal incremental exercise testing elicit maximum physiological responses in highlytrained athletes with cervical spinal cord injury? Front Physiol. 2016;6(419), doi: 10.3389/fphys.2015.00419.

18. Mason BS, Lenton JP, Leicht CA, Goosey-Tolfrey VL. A physiological and biomechanical profile or over-ground, treadmill and ergometer propulsion. J Sports Sci. 2015;32(1):78-91.

19. Hintzy F, Tordi N, Perrey S. Muscular efficiency during arm-cranking and wheelchair exercise: A comparison. Int J Sports Med. 2002:23;408-414.

20. Goosey-Tolfrey VL and Leicht C. Field based testing of wheelchair athletes. Sports Med. 2013;43(2):77-91.

21. Molik B, Laskin JL, Kosmol A, Marszalek J, Morgulec-Asamowicz, Frick T. Relationships between anaerobic performance, field tests and functional level of elite female wheelchair basketball athletes. Hum Mov. 2013;14(4):366-371.

22. Vinet A, Bernard PL, Poulain M, Varray A, Le Gallais D, Micallel J-P. Validation of an incremental field-test for the direct assessment of peak oxygen uptake in wheelchairdependent athletes. Spinal Cord. 1996;34:288-293. 
23. Weissland T, Faupin A, Borel B, Berthoi, S, Lepretre P-M. Effects of modified multi-stage field test on performance and physiological responses in wheelchair basketball players. Biomed Res Int. 2015; doi: 10.1155/2015/245378.

24. de Groot S, Valent LJ, Fickert R, Pluim B, Houdijk H. An incremental shuttle wheel test for wheelchair tennis players. Int J Sports Physiol Perf. 2016;EPUB.

25. Goosey-Tolfrey VL, Tolfrey K. The multistage fitness test as a predictor of endurance fitness in wheelchair athletes. $J$ Sports Sci. 2008;26 (5):511-517.

26. Weissland, T, Faupin, A, Borel, B, Leprete, P-M. Comparison of 30-15 intermittent fitness test and multistage field test on physiological responses in wheelchair basketball players. Front Physiol. 2015. 6;380.

27. Croft, L, Dybrus S, Lenton JP, Goosey-Tolfrey VL. A comparison of the physiological demands of wheelchair basketball and wheelchair tennis. Int J Sports Physiol Perf. 2010,5(3):301-315.

28. Sanchez-Pay, A, Torres-Luque, G, Sanz-Rivas, D. Match activity and physiological load in wheelchair tennis players: a pilot study. Spinal Cord. 2016;54: 229-233.

29. Bernardi M, Guerra E, Di Giacinto, B, Di Cesare, A, Castellano, V, Bhambhani, Y. Field evaluation of Paralympic athletes in selected sports: Implications for training. Med Sci Sports Exerc. 2010;42(6):1200-1208.

30. Abel T, Platen P, Rojas Vega S, Schneider S, Struder HK. Energy expenditure in ball games for wheelchair users. Spinal Cord. 2008;46:785-790.

31. Rhodes J, Mason BS, Perrat B, Smith MJ, Malone LA, Goosey-Tolfrey VL. Activity profiles of elite wheelchair rugby players during competition. Intl J Sports Physiol Perf. 2015;10:318324.

32. Sarro KJ, Misut, MS, Burkett B, Malone LA, Barros RML. Tracking of wheelchair rugby players in the 2008 Demolition Derby final. J Sports Sci. 2010;28(2):193-200.

33. Bloxham LA, Bell GJ, Bhambhani Y, Steadward RD. Time motion analysis and physiological profile of Canadian world cup wheelchair basketball players. Sports Med Training Rehab. 2001;10(3):183-198.

34. Vanlandewijck YC, Evaggelinou C, Daly DJ, Verellen J, Van Houtte S, Aspeslagh V et al. The relationship between functional potential and field performance in elite female wheelchair basketball players, J Sport Sci. 2004;22(7):668-675.

35. Rhodes J, Mason BS, Malone LA, Goosey-Tolfrey VL. Effect of team rank and player classification on activity profiles of elite wheelchair rugby players. J Sports Sci. 2015; 33(19): 2070-2078.

36. Sindall P, Lenton JP, Tolfrey K, Cooper RA, Oyster M, Goosey-Tolfrey VL. Wheelchair tennis match-play demands: Effect of player rank and result. J Sports Sci. 2013;8(1):28-37.

37. de Witte AMH, Hoozemans MJM, Berger MAM. woude van der LHV, Veeger, HEJ Do field position and playing standard influence athlete performance in wheelchair basketball? $J$ Sports Sci. 2016; 34(9): 811-820.

38. Rhodes J, Mason, B, Perrat, B, Smith, M, Goosey-Tolfrey V. The validity and reliability of a novel indoor player tracking system for use within wheelchair court sports. J Sports Sci. 2014;32(17):1639-1647.

39. Sindall P, Lenton JP, Whytock K, Tolfrey K, Oyster M, Cooper R, Goosey-Tolfrey V. Criterion validity and accuracy of global positioning satellite and data logging devices for wheelchair tennis court movement. J Spinal Cord Med. 2013;36:383-393.

40. Sikke van der RMA, Berger MAM, Bregman DJJ, Lagerberg AH, Veeger HEJ. Opportunities for measuring wheelchair kinematics in match settings; reliability of a three inertial sensor configuration. J Biomech. 2015;48(12):3398-3405.

41. Spendiff O, Campbell IG. Influence of pre-exercise ingestion of two concentrations on paraplegic athletes. $J$ Sports Sci. 2005;23(1):21-30.

42. Graham-Paulson TS, Perret C, Watson P, Goosey-Tolfrey VL. Caffeine supplementation improves sprint performance in wheelchair sportsmen. Int J Sports Physiol Perf. 2016;11(2):214-220.

43. Goosey-Tolfrey VL, Paulson TAW, Graham-Paulson TS. Practical considerations for fluid replacement in spinal cord injury. In: Meyer F, Szygula Z, Wilk, B Editors. Fluid balance, 
hydration and athletic performance. CRC Press, Boca Ranton (FL). 2015;333-352.

44. Bergamini E, Morelli F, Marchetti F, Vannozzi G, Polidori L, Paradisi F et al. Wheelchair propulsion biomechanics in junior basketball players: a method for the evaluation of the efficacy of a specific training program. Biomed Res Int. 2015; doi: 10.1155/2015/275965.

45. Goosey-Tolfrey VL. Physiological profiles of elite wheelchair basketball players in preparation for the 2000 Paralympic Games. Adap Phys Activity Quar. 2015;22:57-66.

46. Iturricastillo A, Granados C, Yanci J. Changes in body composition and physical performance in wheelchair basketball players during a competitive season. J Hum Kin. 2015;48:157-165.

47. Gorla J, Costa e Silva A, Borges M, Tanhoffer RA, Godoy, PS, Calegari DC et al. Impact of wheelchair rugby on body composition of subjects with tetraplegia: a pilot study. Arch Phys Med Rehab. 2016;97(1):92-96.

48. Turbanski S, Schmidtbleicher D. Effects of heavy resistance training on strength and power in upper extremities in wheelchair athletes. J Strength Cond Res. 2010; 24(1):8-16.

49. Paulson TAW, Leicht CA, Bishop NC, Goosey-Tolfrey VL. Perceived exertion as a tool to self-regulate exercise in individuals with tetraplegia. Eur J Appl Physiol. 2013;113(1):201209.

50. Paulson TAW, Mason BM, Rhodes J, Goosey-Tolfrey VL. Individualised internal and external training load relationships in elite wheelchair rugby players. Front Physiol. 2015; doi: 10.3389/fphys.2015.00388.

51. Goosey-Tolfrey VL, Foden E, Perret C, Degens H. Effects of inspiratory muscle training on respiratory function and repetitive sprint performance in wheelchair basketball players. $\mathrm{Br} J$ Sports Med. 2010;44,:665-668.

52. West C, Taylor BJ, Campbell IG, Romer LM. Effects of inspiratory muscle training on exercise responses in Paralympic athletes with cervical spinal cord injury. Scand J Med Sci Sports. 2014;5:764-772.

53. Vaile J, Stefanovic B, Askew CD. Effect of lower limb compression on blood flow and performance in elite wheelchair rugby athletes. J Spinal Cord Med. 2016;39(2):206-211.

54. West C, Campbell IG, Mason B, Goosey-Tolfrey VL, Romer LM. Effect of an abdominal binder on measures of field-based fitness in Paralympic wheelchair rugby players. Aus $J$ Sci Med Sport. 2014; 4, 351-355.

55. Mason BS, Woude van der LHV, Goosey-Tolfrey. The ergonomics of wheelchair configuration for optimal performance in the wheelchair court sports. Sports Med. 2013; 43(1):23-38.

56. Curtis KA, Kindlin CM, Reich KM, White DE. Functional reach in wheelchair users: the effects of trunk and lower extremity stabilization. Arch Phys Med Rehabil. 1995;76(4):360367.

57. Mason BS, Woude van der LHV, Goosey-Tolfrey VL. Influence of glove type on mobility performance for wheelchair rugby players. Am J Phys Med Rehabil. 2009;88(7),559-570.

58. Goosey-Tolfrey VL Swainson MG, Boyd C, Atkinson G, Tolfrey K. The effectiveness of hand cooling at reducing exercise-induced hyperthermia and improving distance-race performance in wheelchair and able-bodied athletes. J Appl Physiol. 2008;105(1):37-43.

59. Webborn N, Price MJ, Castle PC, Goosey-Tolfrey VL. Effects of two cooling strategies on thermoregulatory responses of tetraplegic athletes during repeated intermittent exercise in the heat. J Appl Physiol. 2005; 98, 2101-2107.

60. Tribovich, M, Ortega, C, Schroader, J, Fredrickson, M. Effect of a cooling vest on core temperature in athletes with and without spinal cord injury. Top Spinal Cord Inj Rehabil. 2014;20(1):70-80.

61. Castle PC, Kularatne PB, Brewer J, Mauger AR, Austen RA, Tuttle JA et al. Partial heat acclimation of athletes with spinal cord lesion. Eur J Appl Physiol. 2013;113:109-115. 


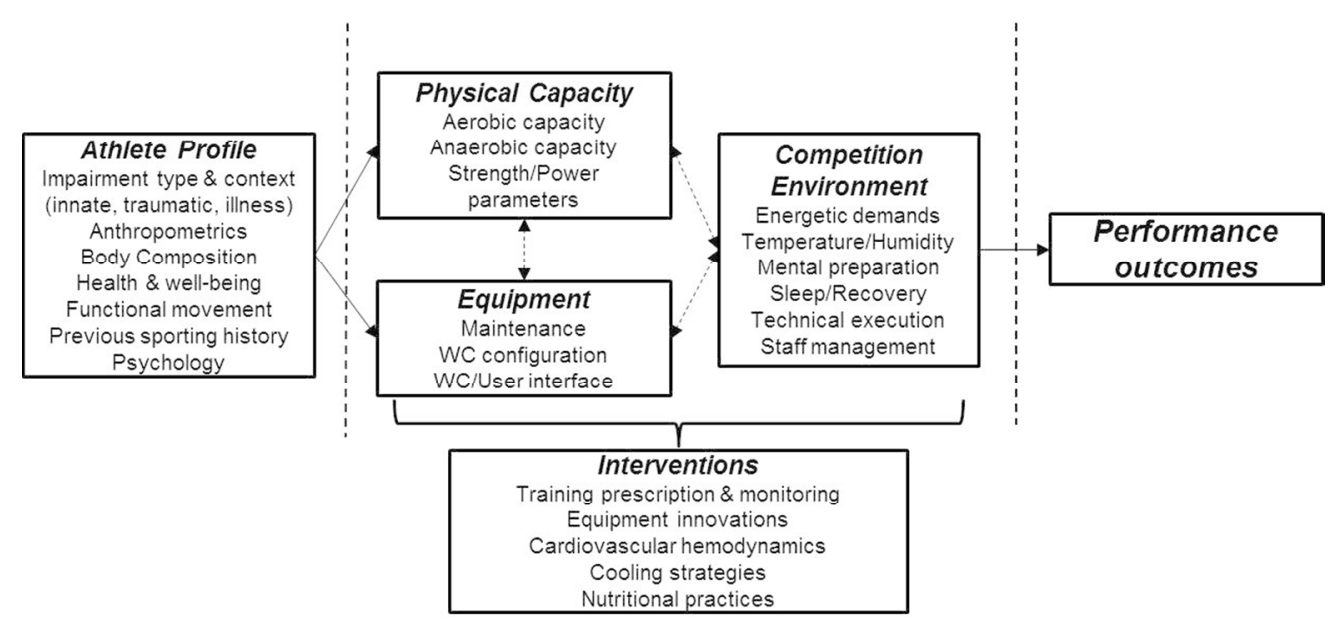

Figure 1 Key components of wheelchair court-sport performance. (WC $=$ Wheelchair). $210 \times 97 \mathrm{~mm}(150 \times 150 \mathrm{DPI})$ 


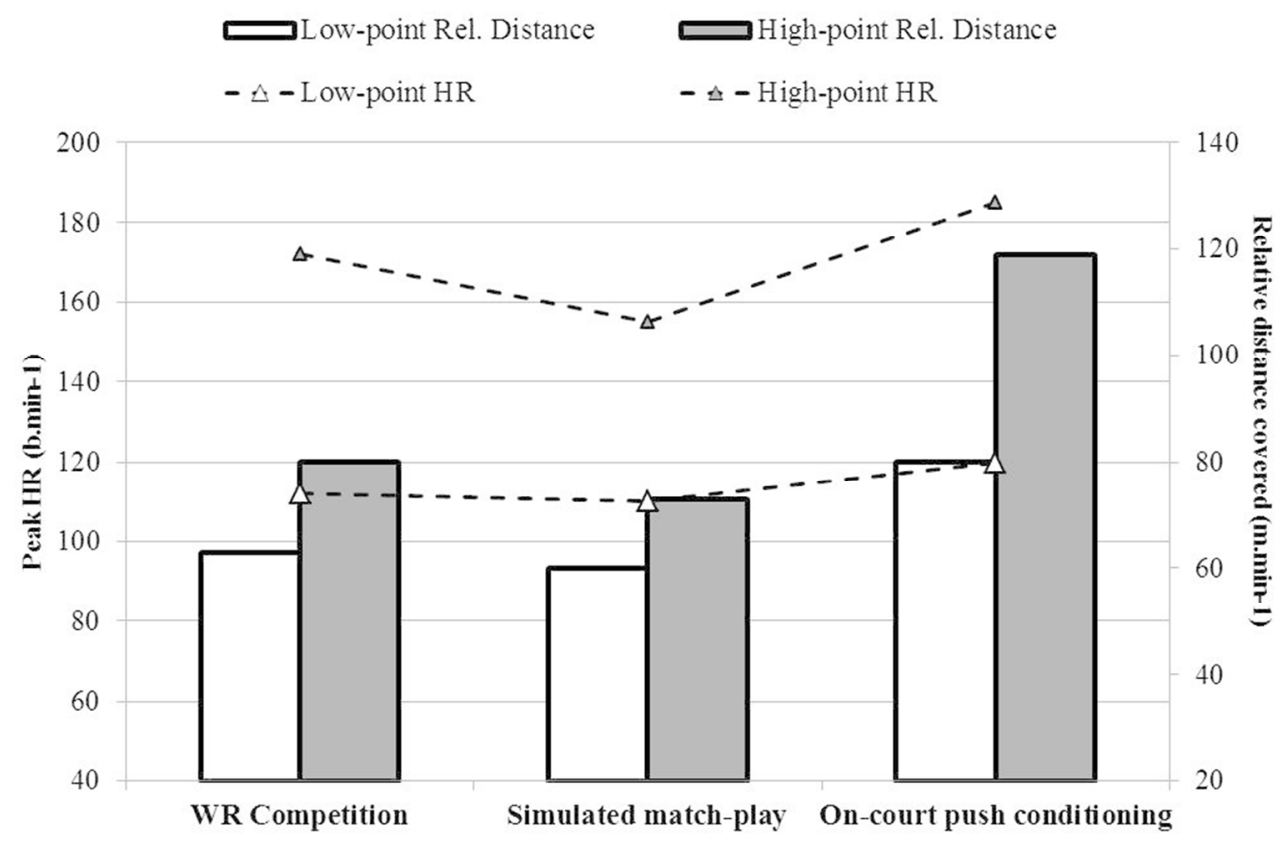

Figure 2 Example heart rate response and distances covered during the same duration wheelchair rugby competition and sport-specific conditioning training for $n=1$ athlete with tetraplegia (classification $=0.5$; low-point player) and $\mathrm{n}=1$ athlete with cerebral palsy (classification $=3.0$; high-point player). ( $\mathrm{HR}=$ heart rate, Rel. Distance $=$ distance covered per minute) (Paulson et al. Unpublished data). $169 \times 111 \mathrm{~mm}(150 \times 150 \mathrm{DPI})$ 